relevant that disease activity was clearly correlated with the concentration and distribution of $\mathrm{C} 3$ in one patient (fig 1); whether this finding applies also to other patients with Behçet's syndrome requires confirmation in a large prospective study.

Our findings also suggest that complement activation occurs in Behçet's syndrome. This may be started by circulating complexes of antigen and antibody, although extravascular complement activation, through the interaction of complementfixing antibodies and tissue antigens, might also produce similar changes. Preliminary evidence in favour of complement activation by immune complexes is provided by finding increased quantities of $\mathrm{IgG}$ in association with macromolecular C3. This concept is further supported by the demonstration of low levels of C4, C2, and C3 before an attack of uveitis in Behçet's syndrome; by the association between other types of uveitis and immune complexes ${ }^{8}$; and by our observations that macromolecular C3 is seen most often in patients with the neuroocular type of the syndrome. The assay we have used, however, provides no information on the amount of immune complexes circulating in the plasma or the way in which they activate the complement system.

It is difficult at present to reconcile the normal levels of $\mathrm{C} 3$ and $\mathrm{C} 4$ and the raised levels of $\mathrm{C} 9$ in Behçet's syndrome with our findings that immune complexes also occur in this disease. Normal levels of C3 and C4, however, are found even though their catabolism has been increased. While it is possible that increased levels of C9 may reflect a temporary imbalance between the synthesis and breakdown of this protein after complement activation, it is more likely that the raised levels of C9 reflect an acute-phase response to immunologically induced tissue injury. ${ }^{3}$ If the presence of immune complexes is confirmed by different techniques the relation of these complexes to cellmediated immune responses will have to be investigated before one understands the immunopathological mechanisms operating in Behçet's syndrome.

\section{References}

1 Shimada, K, et al, Medical Biology, 1974, 52, 234.

2 Kawachi-Takahashi, S, et al, International Archives of Allergy and Applied Immunology, 1975, 48, 161.

${ }^{3}$ Adinolfi, M, and Lehner, T, Clinical and Experimental Immunology, 1976, $25,36$.

4 Lehner, T, MD Thesis, University of London, 1968.

5 Lehner, T, Proceedings of the Royal Society of Medicine, 1968, 61, 515.

- Williams, B D, and Slaney, J M, Annals of Rheumatic Disease, 1977, 36, Supp p 37.

7 Lehner, T, British Medical fournal, 1967, 1, 465.

8 Rahi, A H S, et al, Transactions of the Ophthalmic Society of the UK, 1976, 96, 113.

(Accepted 18 March 1977)

\title{
Vaccination scar with soft-tissue atrophy restored by local insulin treatment
}

\author{
F K AMROLIWALLA
}

British Medical fournal, 1977, 1, 1389-1390

\section{Summary}

A woman who had a deep scar on her left arm as a result of an influenza vaccination was treated with insulin. Monocomponent porcine insulin was injected into each quadrant of the pit. After 82 days' treatment her arm appeared normal and has remained so over seven months. Using insulin's ability to promote fat and protein synthesis is a simple and effective way of treating atrophied scars.

\section{Introduction}

Lipoatrophy caused by insulin treatment in diabetics has been successfully treated by injecting alternative, preferably purer, forms of insulin into the atrophied areas. This technique was first reported by Collens ${ }^{1}$ in 1949 and several subsequent reports have estatlished its usefulness in diabetics.

I can find no reference to the use of this technique in nondiabetics, who may accept ugly atrophied scars as irremediable, except by complex and not altogether successful plastic surgery. This case report should serve as a reminder that a simple and complete remedy does exist.

Royal Air Force Hospital, Ely, Cambridgeshire CB6 1DN F K AMROLIWALLA, BSC, MRCP, consultant physician. Wing Commander

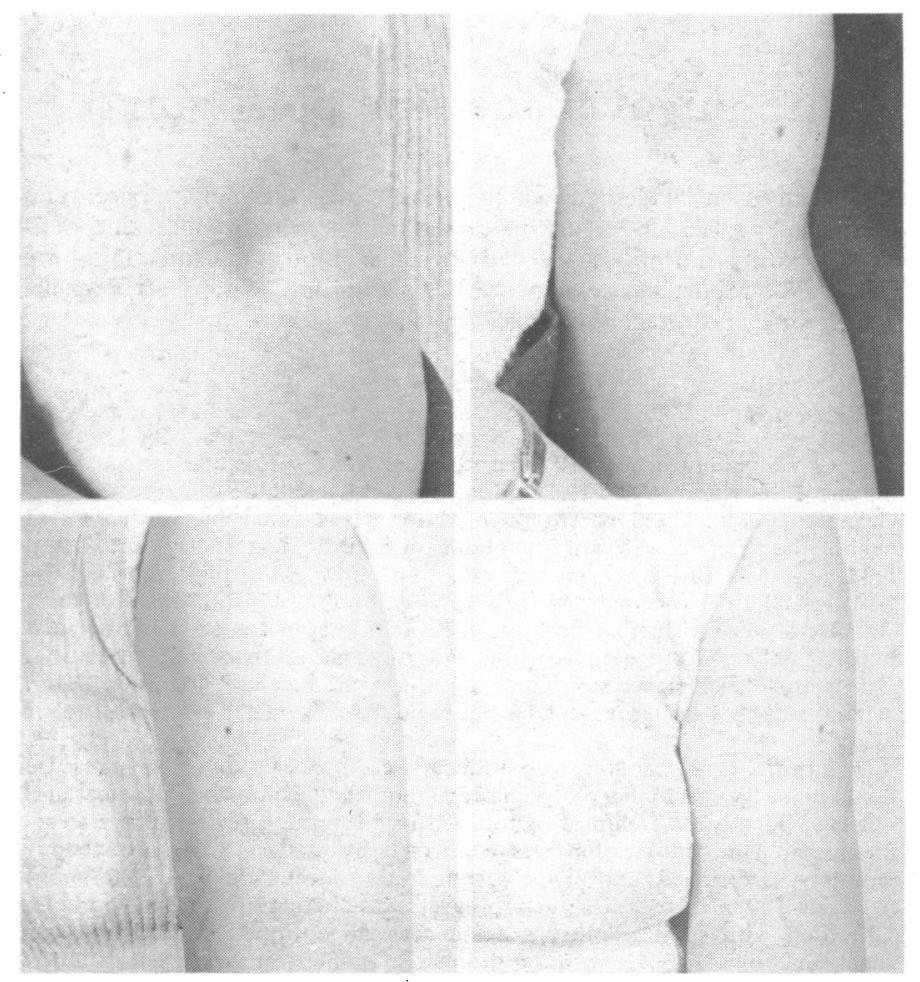

Top: front and side views of left arm showing vaccination scar before treatment. Bottom: front and side views of same arm on 21 May, after treatment had stopped. 


\section{Case report}

A 42-year-old woman with bronchiectasis had received an antiinfluenza vaccination four years earlier. She had reacted to this and developed an unsightly, deeply pitted scar in the middle of her left arm. The scar measured $3 \mathrm{~cm} \times 3 \mathrm{~cm}$ with the central pit reaching "down to the bone." There was no evidence of tethering of soft tissues in the scar to bone below or skin above (see figure).

On 27 February 1976, when she was in hospital for an incidental illness, treatment of the scar was started. Monocomponent porcine soluble insulin was injected in doses of 4 units three times a day before meals. The injection was given subcutaneously with about equal quarters of the dose being injected into each quadrant of the pit, so that the insulin was layered evenly at the base of the scar. Subjectively, clinically, and biochemically she showed no evidence of hypoglycaemia.

Once treatment had been established she left hospital on the sixth day and continued the injections at home, with her husband carrying out the above procedure as instructed. A month later the deep pit had reduced to a mere dimple. On 18 May 1976, after 82 days' treatment, the daily insulin treatment was discontinued as the arm appeared completely normal and no residual evidence of the previously ugly scar could be discerned (fig 2).

At the time of writing, seven months later, the restored area of the arm remained normal.

\section{Discussion}

While any type of insulin would have served in this case, monocomponent porcine insulin was chosen on the theoretical basis of its greater purity and fewer potential local complications.

It is well established that insulin is an anabolic hormone in fat and protein metabolism. Adipose tissue is exquisitely sensitive to insulin, because very small quantities of insulin inhibit lipolysis. The role of insulin in inhibiting lipolysis and stimulating fat synthesis is not clearly understood.: Crofford ${ }^{3}$ has shown in isolated fat cells that the uptake, binding, and destruction of insulin by adipose cells are intimately associated with metabolic effectiveness.

Wool et $a l^{4}$ showed that animal heart or diaphragm muscle incorporated radioactive amino-acids into protein at a much slower rate when deprived of insulin; when insulin was added to the medium the rate of protein synthesis increased within five minutes, even in the absence of glucose. The proposed sequence of protein synthesis by muscle ribosomes included the effect of insulin on translation of messenger ribonucleic acid for a regulatory protein. ${ }^{5}$

Insulin's role in promoting fat and protein synthesis has long been recognised. To use that property to rectify the above type of disfigurement seemed only logical and proved rewarding, not just cosmetically but also psychologically for the patient. The technique is simple, cheap, painless, and worthy of wider use.

I thank the Director-General of Medical Services (RAF) for permission to report this case.

\section{References}

1 Collens, W S, New England fournal of Medicine, 1949, 241, 610.

${ }^{2}$ Albrink, M J, Duncan's Diseases of Metabolism, Endocrinology and Nutrition. Philadelphia, Saunders, 1969.

${ }^{3}$ Crofford, O B, fournal of Biological Chemistry, 1968, 243, 362.

Wool, I G, Rampersad, O R, and Moyer, A N, American fournal of Medicine, 1966, 40, 716.

Wool, I G, and Cavicchi, P, Proceedings of the National Academy of Sciences of the United States of America, 1966, 56, 991.

(Accepted 25 March 1977)
Zinc is an essential element which is now added routinely to parenteral nutrition regimens. ${ }^{1}$ Failure to do so may result in acute zinc deficiency, ${ }^{2}$ but caution is needed because high concentrations are toxic. ${ }^{3}$ We report a case of acute fatal zinc intoxication after an inadvertent intravenous overdose.

\section{Case report}

A 72-year-old woman was referred to St Mary's Hospital with a highoutput enterocutaneous fistula after a second small bowel resection for Crohn's disease. Total parenteral nutrition via a subclavian catheter was begun: the fistula closed within 48 hours and in the next 26 days she gained $5 \cdot 3 \mathrm{~kg}$. The serum zinc concentration rose from 8 to $14.4 \mu \mathrm{mol} / 1(52 \cdot 3-$ $94 \cdot 1 \mu \mathrm{g} / 100 \mathrm{ml}$ ) (normal range $11 \cdot 5-19 \mu \mathrm{mol} / 1 \quad(75 \cdot 2-124 \mu \mathrm{g} / 100 \mathrm{ml})$ ) Because of her satisfactory progress she was transferred back to her original hospital, where araangements were made to continue parenteral nutrition. Owing to a local prescribing error, however, she received $46 \mathrm{mmol}(7 \cdot 4 \mathrm{~g})$ of zinc sulphate over the next 60 hours and was returned acutely ill to $S$ Mary's.

The initial characteristics of the illness were hypotension (blood pressure $80 / 40 \mathrm{~mm} \mathrm{Hg}$ ), pulmonary oedema, diarrhoea and vomiting, jaundice, and oliguria. This bizarre clinical picture led to a thorough review of her treatment, and zinc intoxication was confirmed by analysing the intravenous solutions prescribed and by a serum zinc concentration of $640 \mu \mathrm{mol} /$ $(4184 \mu \mathrm{g} / 100 \mathrm{ml})$. Her subsequent progress was fluctuating but unfavourable. Chelation with sodium calciumedetate was discontinued because of poor renal function. Despite an initial diuresis in response to intravenous fluids and frusemide she remained oliguric, and after a further period of hypotension had a blood urea concentration of $61 \mathrm{mmol} / 1(367 \mathrm{mg} / 100 \mathrm{ml})$ and creatinine clearance of zero. Haemodialysis was undertaken nine times without significant improvement in renal function. Other features of her illness were cardiac arrhythmias and hypotension; hyperamylasaemia (maximum level $3460 \mathrm{IU} / 1$ ) without evidence of acute pancreatitis; a predominantly but not exclusively cholestatic liver function profile, which slowly resolved; acute anaemia (haemoglobin $7.5 \mathrm{~g} / \mathrm{dl}$ ) and thrombocytopenia $\left(14 \times 10^{9} / 1\right)$ by the fifth day; later septic complications with herpes zoster and then Candida albicans and klebsiella septicaemia. She died on the 47th day of illness, with bronchopneumonia.

The salient features at necropsy were: resolving acute tubular necrosis of lower nephron nephrosis type; oedema, macrophage infiltration, and widespread hyaline membrane in the lung; mild centrilobular congestion, scanty bile thrombi, portal tract expansion without increased cellularity, and slight bile duct reduplication in the liver; old ischaemic myocardial fibrosis; and changes consistent with, but not diagnostic of, Crohn's disease in the remaining small bowel.

\section{Comment}

Zinc poisoning has been described after oral administration, ${ }^{3}$ inhalation, ${ }^{3}$ and haemodialysis. ${ }^{4}$ The lethal dose is unknown and the symptoms of severe ingestational poisoning are non-specific: vomiting, diarrhoea, fever, lethargy, and muscle pain and stiffness. Some of these, together with profound anaemia, occurred in a patient on haemodialysis with zinc-contaminated water. ${ }^{4}$ Acute renal failure and acute pancreatitis have also been described. ${ }^{3}$ Zinc seems to be a diffuse cellular toxin which can produce multisystem failure-a feature consistent with the rapid uptake by liver and kidney of most of an injected tracer dose. ${ }^{5}$

Treatment of zinc intoxication must depend on the specific organ failure displayed. Haemodialysis with a zinc-free dialysate is effective in reducing serum concentration, though the kinetics of zinc movement across the membrane are complicated. ${ }^{4}$ Chelating agents remove serum and tissue zinc by increasing excretion. We record this case to 